\title{
Antecedents of trust in online environment: A case of Pakistan
}

\author{
Yaser Zaman $^{a^{*}}$, Raja Ahmed Jamil ${ }^{\mathrm{b}}$ and Zain Kazmi ${ }^{\mathrm{a}}$
}

${ }^{a}$ Master Scholar University of Haripur, Pakistan ${ }^{b}$ Lecturer at University of Haripur, Pakistan

CH R O N I L E A B S T RACT

Article history:

Received October 28, 2015

Received in revised format

November 28, 2015

Accepted January 20, 2016

Available online

January 24, 2016

Keywords:

Online Environment

E-Trust

E-Shopper

E-Business

\begin{abstract}
This study aims to investigate the antecedents of trust including Company Reputation, Website Design, Service Quality, and Security and Privacy Policy in an online environment within the Pakistani context. A pre-tested questionnaire survey is used in order to collect the response of e-shopper in three cities, Abbottabad, Haripur and Islamabad, from 200 Pakistani e-shoppers. SPSS was used to analyze the data and three techniques descriptive statistics, regression analysis and correlation analysis are applied. Findings revealed a positive direct relationship between the independent and dependent variables which validate the earlier studies.
\end{abstract}

C 2016 Growing Science Ltd. All rights reserved.

\section{Introduction}

An online business improvement shows that businesses are expended themselves to the global market (Wilson, 1999) and they will require coping with different customers now for the first time that will have unique custom and belief (Okada, 2006, Barnes et al., 2007). Thus, it will be essential to implement the new concept of market segmentation that contains customers from many countries and environment. Categorizing customers in similar classes allow e-business shopkeeper to act quicker, while relaxing their customers' needs and, therefore, enhancing their sale (Barnes et al., 2007). Buying and selling online or shopping via internet is commonly known as e-commerce and it is expanding very fast as the information technology flourished along with network technology (Wang \& Li, 2012). Ecommerce consists of an online transaction of different services and various kinds of products through the system of electronic selling and buying, which is connected to the internet and a computer network. As it is a new type of the business its activities employ on electronic and digital tools. Parties go through for business by means of internet trading rather than a face-to-face transaction (Guo, 2011). As there is not any detailed study about e-business, this work focuses mainly on growing age consumers, younger than 30years, because they are a group of customers and they are an online shopper providing an

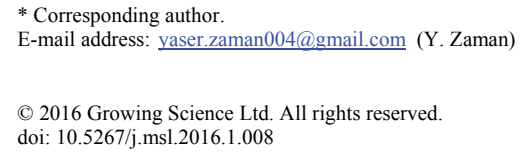


opportunity for e-business as their attitude shows that they are the biggest upcoming target market for e-business. The rate of an online shopper increases day by day all over the world and the new generation has more opportunity to access online transactions (Sato \& Kato, 2005).

This paper presents an empirical investigation to find out how the antecedents of trust including website design, service quality, company reputation, security and privacy policy affect the perception of an online consumer in Pakistani context. This study aims to analyze the relationship of company reputation, website design, security and privacy policy and service quality with the trust building effort of the e-business.

\section{Literature review}

For retaining customers, it is necessary to build the trust of the customers. In an online environment, trust shows the undertaking of customer's attachment to the company and acceptance that company will stand on its words (Ranaweera et al., 2005). In the world of internet, customers' emotions are not much important that website could fulfil their desires by its performance, specifically when a customer has to admit its personal information or at the time of payment via internet so a deficiency in the trust is the major barrier in the way of e-business (Gefen, 2000; Yoon, 2002). That's why the role of trust and its connection to the growth of e-business and its faith to a website is a reference (Gefen, 2000; Haris \& Goode, 2004).

\subsection{Trust}

According to Morgan and Hunt (1994) "Trust in the trade accomplice's unwavering quality and integrity and it is considered to be a key intervening and developing the relationships trades". In addition, according to Moorman et al. (1993) "Trust is the ability to depend on a trade accomplice in whom one has certainty". Trust in the service supplier can be characterized in terms of the apparent believability and altruism of the supplier (Doney \& Canon, 1997). Trust is the degree to which there are sure desires about the supplier's intentions as for one's self in circumstances involving danger (Jeffries \& Reed, 2000). As indicated by Morrison and Firmstone (2000), the primary capacity of trust is to lower the susceptibility; trust also makes customers dangers sensible and in this way makes their decision simplifies. A few researchers keen on long haul connections and consequently rehash buy conduct have guaranteed that trust may in reality be a crucial angle in safeguarding client duty amid troublesome times (Garbarino \& Johnson,1999; Doney \& Canon,1997). Djahantighi and Fakar (2010) expressed that "an online trust is one of the key hindrances to sellers succeeding on the web medium. An absence of trust is liable to dishearten online buyers from taking part in e-trade". The absence of etrust (an online trust) is liable to dissuade any buy over the web (Merrilees \& Fry, 2003). Constantinides (2004) bolsters that an online trust is one of the components that is frequently connected with the disappointment or accomplishment of online endeavors and its multi-dimensional character makes it a muddled issue and he displays an essential trust component which are: "Exchange Security", "Client Data Abuse", "Client Data Safety", "Vulnerability Reducing Elements" and "Assurances Return Policies".

\subsection{Security and privacy policy}

Website security and privacy policy mean that the information gathered from e-consumer are kept secret, and it will be safe and away from the reach of third-party access to this information. Barker et al. (2009) states that is it is hard to define the term privacy in a logically and accurate manner, He shows that the definitions of the privacy often close at aspects that are embracing because it does not define privacy and then close at not addressing all the relevant aspects of the privacy. He introduces the taxonomy of privacy which is classified in four parts.

Information Collection

$>$ Information Processing 
Information Dissemination

Invasion.

Information collection means that the order of the protection arrangement of the destinations, data accumulation need, and protest recognize the approach that information will be gathered. The taxonomy recommends information might be gathered in unequivocally or implicitly. The information processing holds assembling, identification, insecurity, auxiliary use and prohibition. The information dissemination holds information era, information era administration uncovered client framework endowed coincidental behavioral inferred confidentiality, disclosure, exposure, expanded accessibility, blackmail, assignment, and twisting, decimation includes the spread of not the right majority of the data something like the client.

Invasions need interruption and decisional obstruction. Interruption may be identified with issues that intrude the isolation also serenity of the client.

\subsection{Impact of security and privacy policy on trust}

Security and privacy in e-business play a major role in trust-building and making customers mind for e-transaction (Ha, 2004). Wang et al. (2004) suggest that giving privacy and security revelation is a tool of online vendors to make a relationship with customers. The discerned security and privacy needs a critical impact with respect to on the web mark trust (Alam \& Yasin, 2010). Those effects uncovered that learning may be positively connected with trust. Furthermore, internet shopping activities, web retailing act ought to aggravate people, in general, proficient about web transaction security instruments will raise users' trust for web shopping (Wang et al., 2009). The security and privacy's result inclusion has an impact on the mentality towards internet shopping (Keisidou et al., 2011).

\subsection{Website design}

Website design is the format or the look of the web page, how it looks when a consumer visits it, images, colorful texts, and the presentation of the products by the seller for the consumer and literature contains much materials about website design in many dimensions (Susser \& Ariga, 2004). In e-context website is a bridge between consumers and company, and consumer fulfilment of desire makes on the website quality. The website is the sole medium of exchanging thoughts with consumers therefore, the look and shape of the website is very valuable (Barmall et al., 2004; Gummerus et al., 2004). A feature of website design influences on quality of the service provider and customer trust (Wiess et al., 2003; Fienberg \& Kadam, 2002). The latest research has shown that website design components are indicators of consumers trust (Lee \& Lin, 2005; Wolfinbarger \& Gilly, 2001).

Website Information Design: Data outline is connected with the data that is entering on the site page and how the data is sorted out. Earlier studies like Ranganathan and Ganapathy, (2002) have observationally demonstrated that right data on the site creates buy plan.

Website Navigation Design: Route Design of a site is connected with the searching of the site. Regardless of the possibility that definite data is put on the site the client may be leaving the site in the event that he thinks that it is hard to look for the data he needs (Cyr, 2008). Harridge and March (2006) state that legitimate route helps the client spare time and overcome monetary and execution dangers and accordingly prompts trust.

Website Visual Design: Visual configuration of the site manages the tasteful excellence of the site. This incorporates the utilization of design, hues, photos, different textual style sorts to enhance the look and feel of the site. Karvonen (2000) demonstrate that "tasteful excellence" absolutely influence trust. Cyr (2008) contended and experimentally settled that the visual configuration of the site absolutely influences trust. 
Website Communication design: Two path correspondences with seller manage choices to speak with the online store, vicinity of an online salesman, convenient criticism to the online store. These associations with the online store encourage this data trade between an online store and purchase in a simple virtual world. As indicated by Korgaonkar et al. (2006) fitting data services with the seller incorporates peculiarities like an alternative to speaking with the businessperson, surveys from different customers, outside assessment and data trade with an online merchant is a predecessor to buy a plan.

Website Social Presence design: The social vicinity in the Internet space talks about how human warmth and friendliness can be coordinated through the web-interface with a specific end goal to decidedly impact customer mentality towards web shopping. Social vicinity of sites discusses human touch in the site, (Gefen \& Straub, 2004). Social presence is that an online purchasers' feeling of consciousness of the vicinity of the cooperation accomplice and a higher level of social vicinity ought to prompt better observation about the online store.

\subsection{Impact of website design on trust}

Website design can persuade e-buyer trust, varying impacts based on customer's custom and location. Different researchers have reached to the point that customer focuses mostly on the surficial content of site such as images, colors than its substances while trusting a site (Fogg et al., 2002). Others argue that appearance of website adds a small value to website past performance (Sinha et al., 2001). An integrator survey of the experiment-based written works on the antecedents of introductory trust to a business-toconsumer (B2C) e-commerce setting, shows that web plan cues successfully upgrade consumers' introductory trust towards new internet vendors (Karimov et al.,2011). Cyr (2008) observationally demonstrated that data configuration creates trust amongst the clients of the online entries. Yoon (2002) exactly demonstrated that route configuration brings about trust. Mukherjee and Nath (2003) contended that auspicious correspondence creates trust by determining debate and ambiguities.

\subsection{Service quality}

Website service quality refers to the services offered by the business to the e-shopper, how it handles the order, its delivery timing, handling of the objection, returning policy and after sale contact. As per Zeithaml (1988), service quality is characterized as the client's appraisal of the overall brilliance or prevalence of the service. A service may be characterized as a change in the state of a man, or of a decent fitting in with some financial unit, which achieved as the consequence of the movement of some other monetary unit, with the former assertions of the previous individual or monetary unit (Hill, 1977).

Parasuraman et al. (1985) state that clients think that it is harder to assess the nature of services than to assess the nature of items, in light of the fact that review the previous ways surveying end result, as well as the method of providing the service. In addition, clients see quality by contrasting their desires and the real result got from the service. The client's view of service quality may be conceptualized as an exceptionally subjective general assessment, like a state of mind, that is identified with yet not what might as well be called fulfilment (Bitner,1990; Zeithaml,1988) and which happens more than a consistent period of time. In e-business environment standardized service show the struggle of the company to deliver the best quality services via the better conveying system, guaranty, complete and full information about product and services (Emon, 1988; Ha \& stoel, 2008; Yoon \& kim, 2009).

\subsection{Impact of service quality on trust}

The connection between service quality and trust in an online environment was studied by different researchers (Haris \& Goode, 2004; Gummerus et al., 2004; Ribbink \& Colleagues, 2004; Yoon \& Kim, 2009). A customer from various backgrounds makes separate imagination due to changing nature and involvement and gives varying worth to service quality methods (Donthu \& Yoo, 1998; Liu et al., 2001). Herzberg et al.' motivational theory (1959) showing a connection in trust and fulfilment of need when a customer has past e-purchases and if consumer services have enhanced the service quality is a healthy part. Gronroos (1982) recommend that the client's expectations are affected by promoting 
activities, external impacts and informal and recognizes two sorts of quality of the service. 'technical' related to what the client gets from a service and' functional' associated with how the service is conveyed.

\subsection{Firm reputation}

The reputation of the brand is an indication of product or service quality. This variable contains information about service offers, product provided and the good well of the company. Customer searches for this variable in order to minimize the risk and makes himself aware in choosing a firm (Teas \& Agarwal, 2000; Rao et al., 1999). In an online business, reputation plays a major role to build trust and provide information without salesperson about the product to customer to feel to touch and finally to try. A good reputation guarantees the ability, goodwill and secrecy and hence builds the trust of the new buyer (Bramall et al., 2004; Ha, 2004; Park \& Stoel, 2005). Customers from different countries think different about e-business, this is due to the reason of a fast-moving change in product (Tanaka, 1993).

\subsection{Impact of firm reputation on trust}

An organization that goes about on a reliable manner concerning those creation of a certain reputation, particularly when it needs intention (Koufaris \& Sosa, 2004). If a few different people bring the conviction that an organization needs a specific degree of integrity, genuineness, what's more, fairness, then a conceivable client may be prone to accept the individuals' qualities also utilize them on determining that company has a good reputation which camwood trust the organization (Mc-knight et al., 2002). Mc-knight et al. (2002) discovered that agency reputation required a sure sway on trusting convictions in the shares of the organization and additionally on trusting intentions to the organization to new customers. Company reputation is decidedly identified with trust, particularly beginning trust, in the particular organization (Koufaris \& Sosa, 2004).

\section{Methodology}

In this study, the questionnaire survey is used to acquire the data something like antecedents of trust on web business. Four independent variables and one dependent variable are used in this study. The dependent variable is trust and independent variables are company reputation, website design, website service quality, website security and privacy policy. Regression analysis and correlation analysis is used to test the model.

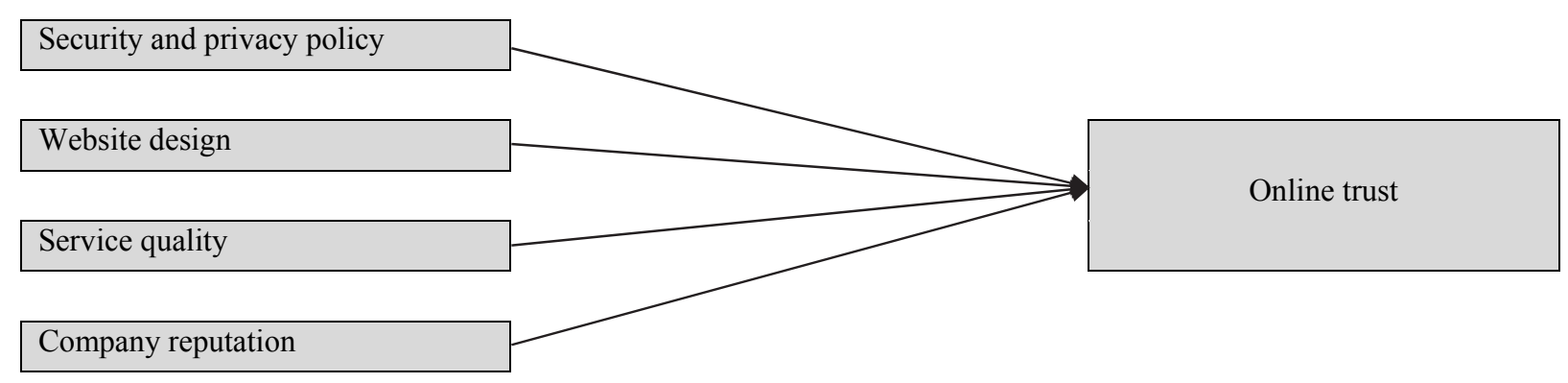

Fig. 1. Theoretical framework

\subsection{Analysis of data}

In this research, data was collected via questionnaire survey from those respondents who made an online purchase in the past. Data has been gathered from three cities of Pakistan including Haripur, Islamabad and Abbottabad. The pre-tested questionnaire is used in this study adopted from San-Martin and Camarero (2012). Every respondent first asks whether or not he made any an online purchase. If their answers were yes then questionnaires were given to them for their responses. 200 questionnaires 
were distributed and from which 191 were received in a usable form. SPSS software is used for analyzing the data in this study. Three statistical procedures are used in dissecting the data including descriptive statistics, correlation analysis and regression analysis.

\subsection{Descriptive statistics}

Descriptive statistics is a technique which tells the reader about the frequency of respondent, it also presents these frequencies in different ways. This study uses the following demographic characteristics. Gender which includes 80 percent male and 20 percent female, Age wise 4.7 percent are below 18 years, 77.6 are lying between 18 to 25 years, 16 percent between 26 and 35 years and above 36 years have 1 percent contribution, on educational basis 3.6 percent are school level, 9.9 percent respondent belong to college, 46 percent are under graduate, 37 percent are graduate and 3 percent are other, Occupation background of the respondent are as follow, 79 percent are students, 5 percent faculties members, 4 percent are entrepreneurs and 12 percent are other, Income level distribution of the respondent are as follow, 60 percent are below 20000, 11 percent lying between 20000 to 29999,15 percent belong to the class of 30000 to 60000 and 13 percent having income more than 60000 .

\subsection{Correlation analysis}

The Correlation is used to figure an association amongst more than two variables. The value of a Pearson's correlation ranges between 0.00 (zero correlation) and 1.00 (perfect correlation). Other elements, for example, aggregation size will figure out whether the connection is critical. Generally, correlations over 0.80 viewed as pretty high.

Table 1

Correlation analysis

\begin{tabular}{llllll}
\hline Name of the variables & $\begin{array}{l}\text { An online } \\
\text { Trust }\end{array}$ & $\begin{array}{l}\text { Website Company } \\
\text { reputation }\end{array}$ & $\begin{array}{l}\text { Website } \\
\text { design }\end{array}$ & $\begin{array}{l}\text { Website Service } \\
\text { quality }\end{array}$ & $\begin{array}{l}\text { Website Security and } \\
\text { privacy policy }\end{array}$ \\
\hline An online Trust & 1 & & & & \\
Website Company reputation & .354 & 1 & 1 & & \\
Website design & .478 & .512 & .431 & 1 & 1 \\
Website Service quality & .568 & .620 & .501 & .475 & 1 \\
Website Security and privacy policy & .401 & .493 & & & \\
\hline
\end{tabular}

** Correlation is significant at the level of 0.01 (two tailed)

\subsection{Regression analysis}

Regression analysis is used in order to check the direction of the relationship between depending variable and independent variables. In this study, the following outcome from regression analysis are used.

Table 2

Model Summery

\begin{tabular}{lllll}
\hline Model & R & R Square & Adjusted R square & Std. the error of estimate \\
\hline 1 & .638 & .407 & .395 & .6236 \\
\hline
\end{tabular}

Table 3

Co-efficient

\begin{tabular}{lcccc}
\hline Model & B & Std. Error & t-value & Sig. \\
\hline Company reputation & 0.353 & 0.068 & 5.203 & 0.000 \\
Website security and privacy & 0.479 & 0.080 & 6.025 & 0.000 \\
Website service quality & 0.630 & 0.066 & 9.499 & 0.000 \\
Website design & 0.541 & 0.072 & 7.484 & 0.000 \\
\hline
\end{tabular}

\section{Discussion and results}

In Table 3, the first column of the coefficient shows the predictor variables (company reputation, website service quality, website security and privacy policy, website design). 
In the second column, the values show the regression equation for predicting the dependent variable from the independent variable

The biggest beta coefficient is .630, which is for website service quality. This implies that this variable makes that strongest commitment on demonstrating the dependent variable, when the variance of other variables remains constant. The coefficient of company reputation is .354 , which means for each percent change for company reputation 35.4 percent expansion clinched alongside an online trust may be predicted, holding all other variables consistent.

The coefficient to website security and privacy .479 with the goal for each unit increment in website security and privacy 47.9 percent change in an online trust is predicted, considering the all other variables are consistent. The coefficient to website design is .541 with the goal that for each one percent change on website design; 54.1 percent change on the web trust is predicted, considering every last bit different variables constant. The sig. column in the table shows that all the variables have significance level at $\mathrm{P}<0.000$. This shows all our hypotheses have been accepted. Model of this study includes, company reputation, website design, website security and privacy policy and website service quality, explaining 40.7 percent of the variance in trust by these four independent variables. The extensive literature review and the findings on overall an online business performance suggested that antecedent of trust was considered important by an online business all over the world. And for overall business performance or organizational developments antecedent of trust are important to reduce risk, hesitation, cost, customer complaints, and, on the other hand, increase profit, productivity, and competitive position to stay in business. Findings also indicate that service quality is the essential variable in generating and promoting trust of the e-shopper, security and privacy policy improved the payment method from the consumer side and delivery process from the business side. All four hypotheses were confirmed by the data. Our results are also supported by the literature. Previous research of different author also supported our finding.

\section{Conclusion}

As the result of this study was obtained through questionnaire survey it has a wide range of practical implications and it has been found that trust emerges as the key antecedent on an online business. First, an antecedent of trust has positive effects on business and whole business performance. Second, antecedents of trust are decisive factors in determining the success of organizations and their overall business performances. Third, the research findings can imply that it is very important for all factors to be present and to make sure that every factor contributes its part for the success of the overall business performance. Fourth, service quality builds the trust of e-shopper and it has a greater impact over the customer to change their minds about the e-business. Fifth, security and privacy policy are the cry of the day, the website which has the most secure business transaction process attracts more consumer compared to those which expose the privacy of the customers. Sixth, company reputation attracts the customer towards the business if the website has a well-known brand moves towards it compared to its competitors. Seventh, website design provides the easiest way for the e-shopper and saves their time, which in turned develops the trust of the customer about that business

In other words, we can say that if a few elements are missing, it is possible to obtain the required level of the result but for long term success of business, all factors must play their roles to improve the performance.

\subsection{Recommendation and implications}

Antecedents of trust are the most important aspects of the online business. It plays a vital role for the success of any online business. This research is applicable in all those businesses that run their operations through the internet. It has a wide range of applications for an online business. In order to build the trust of the e-shopper, we recommend the following suggestions on the basis of our finding. First, business must develop a brand name which must have a unique identity and at any cost do not let reputation loses. Second, as much as possible, a business could make website consumers friendly and easily to use so that customer could easily interact with the business. Third, service quality makes 
customers close to the business and hence this closeness builds trust. It is suggested that quality of services never be lower if a business wants to sustain its customers.

\subsection{Limitations of the study}

Antecedents of trust in an online environment are perhaps a new study in the Pakistani context. In Pakistan, the culture of an online buying and selling is at its grass root level. The majority of the population shops from physical stores. Therefore, the following are the limitations of this study. First, data has been collected from three cities of Islamabad, Haripur and Abbottabad, which might not be the true representation of the Pakistani culture. Second, sample of data contains 191 respondents having experience of an online shopping which is a little bit low, a larger number of data might reflect a true picture.

\section{References}

Barker, K., Askari, M., Banerjee, M., Ghazinour, K., Mackas, B., Majedi, M., \& Williams, A. (2009). A data privacy taxonomy. In Dataspace: The Final Frontier (pp. 42-54). Springer Berlin Heidelberg.

Barnes, S. J., Bauer, H. H., Neumann, M. M., \& Huber, F. (2007).Segmenting cyberspace: a customer typology for the internet.European Journal of Marketing, 41(1/2), 71-93.

Barnes, S. J., Bauer, H. H., Neumann, M. M., \& Huber, F. (2007). Segmenting cyberspace: a customer typology for the internet. European Journal of Marketing, 41(1/2), 71-93.

Bramall, C., Schoefer, K., \& McKechnie, S. (2004). The determinants and consequences of consumer trust in eretailing: a conceptual framework. Irish Marketing Review, 17(1/2), 13.

Bitner, M. J. (1990). Evaluating service encounters: the effects of physical surroundings and employee responses. The Journal of Marketing, 54(2), 69-82.

Coles, G. M., \& Smart, W. J. (2011, July). Building trust in online customers. In Software Engineering, Artificial Intelligence, Networking and Parallel/Distributed Computing (SNPD), 2011 12th ACIS International Conference on (pp. 93-98). IEEE.

Constantinides, E. (2004). Influencing the online consumer's behavior: the Web experience. Internet research, 14(2), 111-126.

Cyr, D. (2008). Modeling web site design across cultures: relationships to trust, satisfaction, and e-loyalty. Journal of Management Information Systems, 24(4), 47-72.

Donthu, N., \& Yoo, B. (1998). Cultural influences on service quality expectations. Journal of service research, 1(2), 178-186.

Doney, P. M., \& Cannon, J. P. (1997). An examination of the nature of trust in buyer-seller relationships. the Journal of Marketing, 61(2), 35-51.

Djahantighi, F. S., \& Fakar, E. (2010). Factors Affecting Customer's Trends for Reservation Foreign Hotels via Internet in Iran. International Bulletin of Business Administration, 7(2), 6-14.

Emons, W. (1988). Warranties, moral hazard, and the lemons problem. Journal of Economic Theory, 46(1), 16-33.

Feinberg, R., \& Kadam, R. (2002). E-CRM Web service attributes as determinants of customer satisfaction with retail Web sites. International Journal of Service Industry Management, 13(5), 432-451.

Fogg, B. J. (2002). Persuasive technology: using computers to change what we think and do. Ubiquity, 2002(December), 5.

Fogg, B. J., Soohoo, C., Danielson, D., Marable, L., Stanford, J., \& Tauber, E. R. (2002). How do people evaluate a web site's credibility?

Garbarino, E., \& Johnson, M. S. (1999). The different roles of satisfaction, trust, and commitment in customer relationships. The Journal of Marketing, 63(2), 70-87.

Gefen, D. (2000). E-commerce: The role of familiarity and trust. Omega: The International Journal of Management Science, 28, 725-737. doi: 10.1016. S0305-04830000021-9.

Gefen, D., \& Straub, D. W. (2000). The relative importance of perceived ease of use in IS adoption: a study of ecommerce adoption. Journal of the Association for Information Systems, 1(1), 8.

Gefen, D., \& Straub, D. W. (2004). Consumer trust in B2C e-Commerce and the importance of social presence: experiments in e-Products and e-Services. Omega, 32(6), 407-424.

Gronroos, C. (1994). From marketing mix to relationship marketing: towards a paradigm shift in marketing. AsiaAustralia Marketing Journal, 2(1), 9-29.

Gummerus, J., Liljander, V., Pura, M., \& Van Riel, A. (2004). Customer loyalty to content-based web sites: the case of an online health-care service. Journal of services Marketing, 18(3), 175-186.

Guo, M. (2011, May). Protection of consumer right to a fair transaction in E-commerce. In Business Management and Electronic Information (BMEI), 2011 International Conference on (Vol. 2, pp. 5-8). IEEE.

Guo, M. (2012). A Comparative study on consumer right to privacy in e-commerce. 
Ha, H. Y. (2004). Factors influencing consumer perceptions of brand trust online. Journal of Product \& Brand Management, 13(5), 329-342.

H. L. Wang and S. Y. Li., (2012).Research on Some Problems of E-Commerce Law. Peking University Press, Beijing, 2012.

Ha, S., \& Stoel, L. (2009). Consumer e-shopping acceptance: Antecedents in a technology acceptance model. Journal of Business Research, 62(5), 565-571.

Harris, L. C., \& Goode, M. M. (2004). The four levels of loyalty and the pivotal role of trust: a study of online service dynamics. Journal of retailing, 80(2), 139-158.

Harridge-March, S. (2006). Can the building of trust overcome consumer perceived risk online?. Marketing Intelligence \& Planning, 24(7), 746-761.

Herzberg, F., Mausner, B., \& Snyderman, B. B. (1959). The Motivation to Work, John Wiley \& Sons. Inc., New York, 195.

Hill, T. P. (1977). On goods and services. Review of income and wealth, 23(4), 315-338.

Jeffries, F. L., \& Reed, R. (2000). Trust and adaptation in relational contracting. Academy of Management Review, 25(4), 873-882.

Karvonen, K. (2000, November). The beauty of simplicity. In Proceedings on the 2000 conference on Universal Usability (pp. 85-90). ACM.

Karimov, F. P., Brengman, M., Van Hove, L., \& Van, L. (2011). The effect of website design dimensions on initial trust: a synthesis of the empirical literature. Journal of Electronic Commerce Research, 12(4), 272-301.

Keisidou, E., Sarigiannidis, L., \& Maditinos, D. (2011). Consumer characteristics and their effect on accepting online shopping, in the context of different product types. International Journal of Business Science \& Applied Management, 6(2), 31-51.

Koufaris, M., \& Hampton-Sosa, W. (2004). The development of initial trust in an online company by new customers. Information \& management, 41(3), 377-397.

Lee, G. G., \& Lin, H. F. (2005). Customer perceptions of e-service quality in online shopping. International Journal of Retail \& Distribution Management, 33(2), 161-176.

Liu, B. S. C., Furrer, O., \& Sudharshan, D. (2001). The relationships between culture and behavioral intentions toward services. Journal of Service Research, 4(2), 118-129.

Koufaris, M., \& Hampton-Sosa, W. (2004). The development of initial trust in an online company by new customers. Information \& management, 41(3), 377-397.

McKnight, D. H., Choudhury, V., \& Kacmar, C. (2002). The impact of initial consumer trust on intentions to transact with a web site: a trust building model. The Journal of Strategic Information Systems, 11(3), 297-323.

Merrilees, B., \& Fry, M. L. (2003). E-trust: the influence of perceived interactivity on e-retailing users. Marketing Intelligence \& Planning, 21(2), 123-128.

Morgan, R. M., \& Hunt, S. D. (1994). The commitment-trust theory of relationship marketing. the Journal of Marketing, 58(3), 20-38.

Montoya-Weiss, M. M., Voss, G. B., \& Grewal, D. (2003). Determinants of online channel use and overall satisfaction with a relational, multichannel service provider. Journal of the Academy of Marketing Science, 31(4), 448-458.

Moorman, C., Zaltman, G., \& Deshpande, R. (1992). Relationships between providers and users of market research: The dynamics of trust. Journal of marketing research, 29(3), 314-328.

Moorman, C. (1993). Factors Affecting Trust in Market Relationships. Journal of Marketing, 57 (January), 81-101.

Morrison, D. E., \& Firmstone, J. (2000). The social function of trust and implications for e-commerce. International Journal of Advertising, 19(5), 599-623.

Mukherjee, A., \& Nath, P. (2003). A model of trust in online relationship banking. International Journal of Bank Marketing, 21(1), 5-15.

Okada, H. (2006). ''E-commerce', Retrieved from http://www.ai.u-hyogo.ac.jp (accessed January 26, 2006).

Parasuraman, A., Zeithaml, V. A., \& Berry, L. L. (1985). A conceptual model of service quality and its implications for future research. The Journal of Marketing, 49(4), 41-50.

Rao, A. R., Qu, L., \& Ruekert, R. W. (1999). Signaling unobservable product quality through a brand ally. Journal of Marketing Research, 36(2), 258-268.

Ranaweera, C., McDougall, G., \&Bansal, H. (2005). A model of online customer behavior during the initial transaction: Moderating effects of customer characteristics. Marketing Theory, 5(1), 51-74.

Ribbink, D., Van Riel, A. C., Liljander, V., \& Streukens, S. (2004). Comfort your online customer: quality, trust and loyalty on the internet. Managing Service Quality: An International Journal, 14(6), 446-456.

Sato, N., \& Kato, Y. (2005). Youth marketing in Japan. Young Consumers, 6(4), 56-60.

San-Martín, S., \& Camarero, C. (2012). A cross-national study on online consumer perceptions, trust, and loyalty. Journal of Organizational Computing and Electronic Commerce, 22(1), 64-86.

Shah Alam, S., \& Mohd Yasin, N. (2010). What factors influence online brand trust: evidence from online tickets buyers in Malaysia. Journal of theoretical and applied electronic commerce research, 5(3), 78-89. 
Sinha, A., \& Chandrakasan, A. (2001). Dynamic power management in wireless sensor networks. Design \& Test of Computers, IEEE, 18(2), 62-74.

Smith, R., \& Shao, J. (2007). Privacy and e-commerce: a consumer-centric perspective. Electronic Commerce Research, 7(2), 89-116.

Susser, B., \& Ariga, T. (2006). Teaching e-commerce Web page evaluation and design: a pilot study using tourism destination sites. Computers \& Education, 47(4), 399-413.

Tanaka, H. (1993). Brand equity kenkyuu no tenkai. Development of brand equity research”), Marketing Journal, 51 , $88-92$.

Wang, S., Beatty, S. E., \& Foxx, W. (2004). Signaling the trustworthiness of small online retailers. Journal of interactive marketing, 18(1), 53-69.

Wang, C. C., Chen, C. A., \& Jiang, J. C. (2009). The impact of knowledge and trust on e-consumers' online shopping activities: an empirical study.Journal of computers, 4(1), 11-18.

Wilson, E. O. (1999). Consilience: The unity of knowledge (Vol. 31). Vintage.

Wilson, T. (1999). Not a global village after all. Internetweek, (792), 13.

Wolfinbarger, M., \& Gilly, M. C. (2001). Shopping online for freedom, control, and fun. California Management Review, 43(2), 34-55.

Yoon, S. J. (2002). The antecedents and consequences of trust in online-purchase decisions. Journal of interactive marketing, 16(2), 47-63.

Yoon, C., \& Kim, S. (2009). Developing the causal model of online store success. Journal of Organizational Computing and Electronic Commerce, 19(4), 265-284.

Zeithaml, V. A., Bitner, M. J., \& Gremler, D. D. (2006). Services marketing: Integrating customer focus across the firm.

Zeithaml, V. A. (1988). Consumer perceptions of price, quality, and value: a means-end model and synthesis of evidence. The Journal of Marketing, 2-22.

\section{Appendix}

\begin{tabular}{|c|c|}
\hline REP1 & This website has a good reputation \\
\hline REP2 & The website brand is well-known \\
\hline SEC1 & It is safe and has a privacy policy regarding customer information \\
\hline SEC2 & The site informs the customer about security and privacy policies \\
\hline SEC3 & I feel safe when sending personal information \\
\hline SEC4 & I think my rights regarding my personal details are respected \\
\hline SEC5 & I think the site has mechanisms that warrantee the safe transmission of its user's information. \\
\hline QUA1 & Detailed information is provided regarding the range of products and services offered \\
\hline QUA2 & A warranty is provided to cover possible unforeseen events or product/service faults \\
\hline QUA3 & Compliance with promised quality and delivery term conditions \\
\hline QUA4 & It offers customized products and services \\
\hline QUA5 & There is a possibility of returning the product in case of dissatisfaction \\
\hline DES1 & Browsing on this website is easy \\
\hline DES2 & I perceive the shopping experience as if I were buying in a physical store \\
\hline DES3 & The site has an attractive, modern and professional design \\
\hline DES4 & Buying is fun because the site contains images \\
\hline TRU1 & I think this website keeps its promises \\
\hline TRU2 & I think the information provided on this website is true and honest \\
\hline TRU3 & I think I can trust this website \\
\hline TRU4 & This website never issues false statements \\
\hline TRU5 & This website stands out for its honesty and transparency when offering its products to users \\
\hline TRU6 & This website's behavior is ethical \\
\hline
\end{tabular}

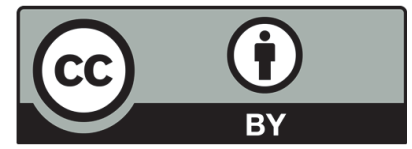

(C) 2016 by the authors; licensee Growing Science, Canada. This article is an open access article distributed under the terms and conditions of the Creative Commons Attribution (CC-BY) license (http://creativecommons.org/licenses/by/4.0/). 